\title{
Symptom Trajectories Throughout Two Family Therapy Treatments for
}

\section{Adolescent Anorexia Nervosa}

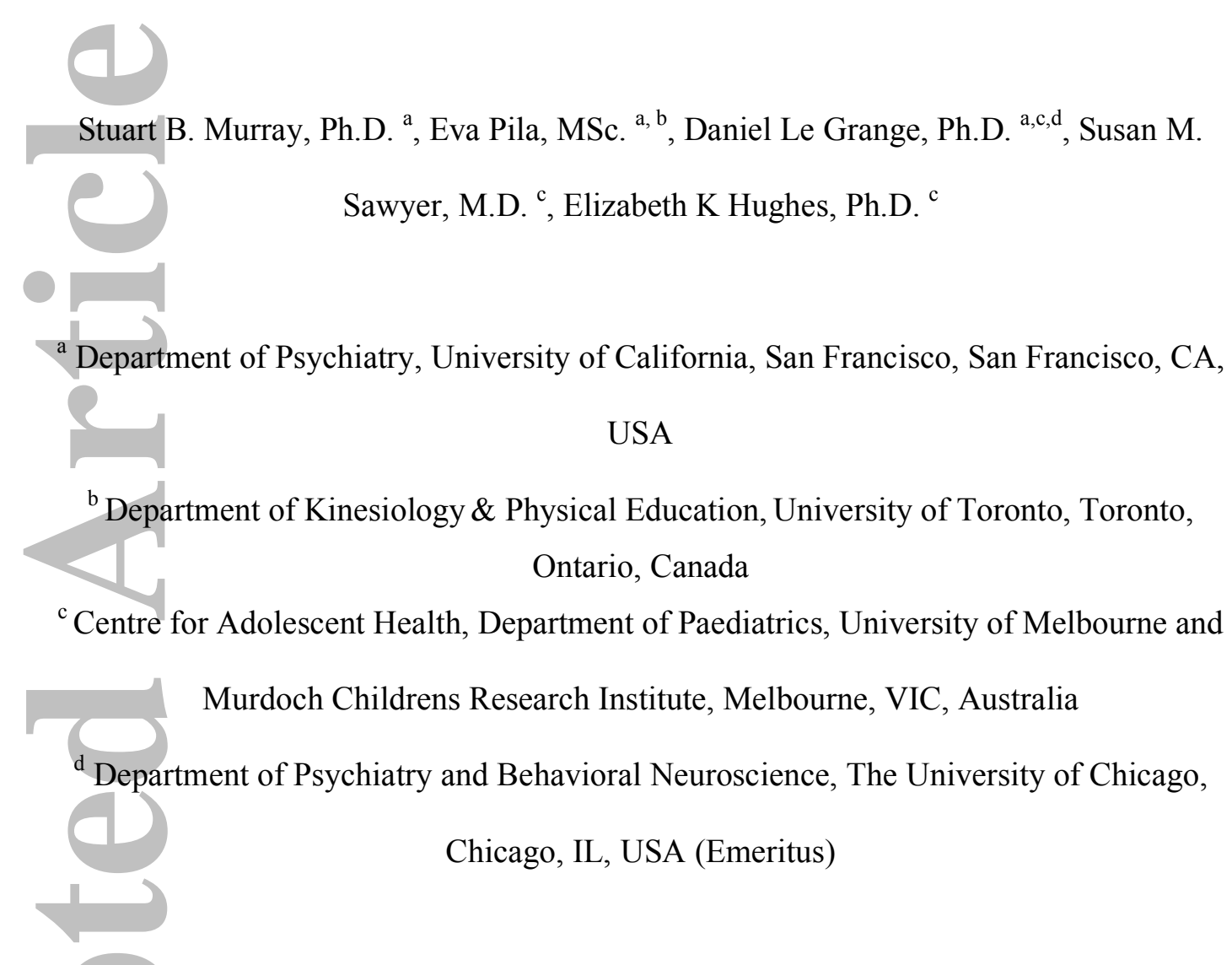

Keywords: Anorexia nervosa, family-based treatment, parent-focused therapy, symptom trajectory

Correspondence: Elizabeth K. Hughes, Ph.D., Centre for Adolescent Health, Royal Children's Hospital, 50 Flemington Road, Parkville VIC 3052 Australia. Phone: +61 39345 4738. Email: Libby.Hughes@rch.org.au

Word count: 2061

This is the author manuscript accepted for publication and has undergone full peer review but has not been through the copyediting, typesetting, pagination and proofreading process, which may lead to differences between this version and the Version record. Please cite this article as doi:10.1002/ eat.22776. 


\begin{abstract}
Objective: This study aimed to examine the trajectory of symptom remission and affective functioning throughout the course of two family-based treatments for adolescent anorexia nervosa (AN); family-based treatment (FBT) and parent-focussed treatment (PFT).

Method: Participants were 107 adolescents $\left(M_{\text {age }}=15.5\right.$ years, $\left.S D=1.5\right)$ with a primary diagnosis of $\mathrm{AN}$ who participated in a randomized clinical trial comparing FBT $(\mathrm{N}=55)$ and PFT $(\mathrm{N}=51)$. Patient weight and self-reported assessments of dietary restraint and positive and negative affect were recorded at regular intervals throughout treatment.

Results: Multilevel models revealed increases in weight $(\beta=0.33, p<.001)$ and positive affect $(\beta=0.03, p<.001)$, and decreases in dietary restraint $(\beta=-0.03, \mathrm{p}<.001)$ and negative affect $(\beta=-0.04, \mathrm{p}<.001)$ over the course of treatment. No significant effects emerged by treatment type.

Discussion: These findings suggest that PFT may bring about comparable trajectories of weight gain and reduced dietary restraint as conjoint FBT, despite adolescents not being directly involved in treatment. These findings also highlight that the exclusively behavioral focus throughout both PFT and FBT is associated with significant increments in positive affect and significant reductions in negative affect.
\end{abstract}

Abstract word count: 196/200

International Journal of Eating Disorders 
Symptom Trajectories Throughout Two Family Therapy Treatments for Adolescent Anorexia Nervosa

Family-based treatment (FBT) is among the most empirically supported treatments for medically stable adolescent anorexia nervosa (AN). However, with approximately one-third of adolescents achieving remission of weight and cognitive symptoms at end-of-treatment (EOT), 12-month follow-up (Lock et al., 2010), and at 4-year follow-up (Le Grange et al., 2014), there is much room for augmenting the efficacy of FBT. One potential avenue for enhancing outcomes relates to treatment delivery in a format whereby parents and adolescents are seen separately. Early clinical trials of separated family therapy for adolescent AN illustrated significant symptom improvement (Le Grange et al., 1992), and improved effectiveness in families with high levels of expressed emotion (Eisler et al., 2000). A manualized form of separated FBT, termed parent-focussed treatment (PFT), is characterized by adolescents being seen by a nurse for brief medical screening, supportive counselling and weight monitoring, while only parents are included in treatment sessions (Hughes et al, 2015). In the first randomized clinical trial (RCT) comparing PFT to conjoint FBT, PFT demonstrated greater rates of symptom remission at EOT $(43.1 \%>21.8 \%)$, and comparable remission rates at 6- and 12-month follow-up (Le Grange et al., 2016).

Alongside these promising post-treatment findings, this secondary analysis aims to index symptom trajectories throughout both treatments in this FBT vs. PFT trial. Whereas weight status and cognitive psychopathology were not significantly different at EOT in FBT and PFT, their trajectory throughout treatment serves as an important prognostic indicator of overall treatment outcome (Doyle et al., 2010). Moreover, despite conjoint FBT typically achieving weight restoration faster than comparator family- (Agras et al., 2014) or individual treatment (Lock et al., 2010), a further question relates to the trajectory of 
cognitive and affective symptom remission in adolescents throughout treatment. Affective states have been identified as integral factors driving AN psychopathology (Lavender et al., 2013) yet are generally overlooked in the treatment of AN, and may potentially contribute to future relapse (Federici \& Kaplan, 2008). In the conjoint FBT vs. PFT trial (Le Grange et al., 2016), positive and negative affect did not emerge as moderators of remission at EOT or follow-up, although somewhat discrepantly, an earlier RCT suggested greater affective symptom remission at EOT in a conjoint form of family therapy for AN, relative to a separated format (Eisler et al., 2000). Despite these findings, the potential for affective states to fluctuate throughout the course of treatment is an important and overlooked question.

The current study aims to extend the findings of the original RCT (Le Grange et al., 2016) by explicating trajectories of change in relevant markers of remission (i.e., weight, dietary restraint, positive and negative affect) throughout both FBT and PFT, as opposed to reporting categorical definitions of remission at post-treatment. We hypothesized that weight and dietary restraint would improve at a faster rate over the course of PFT, relative to FBT. However, given the absence of adolescents from PFT sessions, we hypothesized that positive and negative affect would improve at a faster rate in FBT, relative to PFT.

\section{Method}

\section{Participants and Procedures}

Participants were 107 adolescents with AN, ranging from age 12-18 years $\left(M_{\text {age }}=15.5\right.$ years, $S D=1.5)$, who participated in an RCT comparing FBT $(\mathrm{n}=55)$ and PFT $(\mathrm{n}=51)(\mathrm{Le}$ Grange et al., 2016). As outlined in the main outcome paper (Le Grange et al., 2016), participants were predominantly female (87.7\%), Australian-born (92.5\%), and from intact families $(63.2 \%)$. The mean illness duration was 10.5 months $(S D=8.8)$, percent $\mathrm{mBMI}$ was $81.9 \%(S D=6.1)$, and mean Global EDE was $2.15(S D=1.68)$. The majority of the 
sample (63.2\%) reported comorbid psychiatric conditions (mostly mood disorder); while $7.5 \%$ were taking psychiatric medication. Most participants $(84.9 \%)$ completed treatment (i.e., at least $50 \%$ of prescribed 18 -session treatment dose). Full procedural details, participant details, exclusion criteria, attrition rates, therapist supervision and adherence, and analyses of missing data have been previously published (Hughes et al., 2014; Le Grange et al., 2016).

\section{Treatments}

Family-Based Treatment (FBT): FBT is a manualized family therapy-based treatment for adolescent AN, which has been well explicated (Lock \& Le Grange, 2013). FBT is conducted in a conjoint format in which adolescents, parents and siblings attend treatment sessions together.

Parent-Focused Treatment (PFT): PFT, also manualized (Hughes et al., 2015), is an adaptation of FBT that retains the core theoretical tenets of FBT but differs inasmuch as adolescents are not directly included in treatment sessions. In PFT, a nurse weighs the adolescent during a brief medical check and provides brief supportive counselling. Weight data is communicated to the therapist and openly discussed with parents in sessions. No family meal is conducted.

\section{Measures}

Patient weight: Patient weight was recorded at each session throughout both treatments. Dietary Restraint: The Dietary Restraint subscale of the Eating Disorder ExaminationQuestionnaire (EDE-Q) (Fairburn \& Beglin, 1994) consists of 5 items that require participants to indicate their engagement in various dimensions of dietary restraint over the preceding 28 days, ranging from 0 (no days) to 6 (every day). Dietary Restraint was recorded on a fortnightly basis for the first 12 weeks and at EOT, and served as a proxy for cognitive ED psychopathology since full EDE-Q completion only occurred at week 12, 
EOT and follow-up time points, with a view to minimizing participant burden throughout treatment. The Dietary Restraint subscale of the EDE-Q demonstrates good psychometric properties (Mond, et al., 2004), and in the current study demonstrated good baseline concordance with the Eating Disorder Examination (Cooper \& Fairburn), $r=.851$, and

Cronbach's $\alpha$ ranged from .89 to .90 .

Positive and Negative Affect Scale (PANAS): The PANAS is a well-validated self-report measure of global positive and negative affect (Watson et al., 1988). Participants rate the extent to which they have experienced negatively-valenced emotions (i.e., irritable) and positively-valenced emotions (i.e., happy) in the preceding 2-weeks, on a 5-point scale ranging from 1 (very slightly or not at all) to 5 (extremely). The PANAS was completed fortnightly for the first 12 weeks and at EOT. Cronbach's $\alpha$ in the current study ranged from .88 to .91 for negative affect, and .89 to .92 for positive affect.

\section{Analyses}

Following descriptive analyses, trajectories of main variables of interest were modelled using hierarchical linear modelling. In the first step, a Level-1 model was estimated to examine longitudinal changes in each variable of interest (i.e., weight, dietary restraint, positive affect, negative affect), as a function of time (i.e., weeks in treatment), and a residual term. In these models, the intercept represented treatment onset levels of each weight/restraint/affect variable, and the slope parameter for time represented average linear change over the course of treatment for the entire sample. Meanwhile, the between-person variance associated with this slope indicates whether participants differed from one another in their rate of change. In a subsequent step, a Level-2 model was estimated to investigate the between-person effects of treatment allocation (i.e., FBT or PFT) on the variability in participants' intercept (i.e., treatment onset levels of weight/restraint/affect), and slope values (i.e., weekly change in weight/restraint/affect). In the case where significant cross- 
level interaction effects were observed, an estimation of simple slopes of change was subsequently conducted. In all models, the reported effects represent restricted maximum likelihood estimation and robust standard errors.

\section{Results}

Descriptive findings and visual inspection of the data revealed no evidence of nonlinear trends.

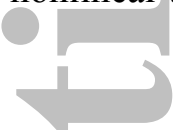

[Insert Figure 1 about here]

Findings for symptom trajectory models are presented in Table 1. There was a significant intercept for weight, dietary restraint, negative affect, and positive affect, indicating that treatment onset levels of each outcome were significantly different from zero. In addition, the slope parameters for time were positive for weight, and negative for dietary restraint, indicating that weight increased, while dietary restraint decreased over the course of treatment. Meanwhile, there were significant slope effects for negative affect and positive affect, whereby participants reported decreases in negative affect and increases in positive affect over the course of treatment. In addition, significant between-person variability was observed for restraint $\left(\sigma^{2}=0.005, p<.001\right)$, positive $\left(\sigma^{2}=0.001, p<.001\right)$ and negative affect $\left(\sigma^{2}=0.001, p<.001\right)$, but not weight $\left(\sigma^{2}=0.005, p=0.06\right)$. This between-person variability indicated that participant scores of restraint differed from one another in their rate of change over the course of treatment. Subsequently, the Level-2 models revealed no significant effects of treatment type (i.e., FBT or PFT) on the treatment onset levels of each variable, nor any significant cross-level interactions. For the most parsimonious presentation of trajectories over time, combined trend lines for both treatments are depicted in the modeling of each variable (Figure 1).

[Insert Table 1 about here]

\section{Discussion}


This study examined trajectories of weight status, self-reported dietary restraint, and global affective functioning throughout the course of two family therapy-based treatments for adolescent AN; FBT and PFT. Contrary to study hypotheses, we found comparable trajectories of weight normalization and dietary restraint across FBT and PFT, and comparable trajectories of positive and negative affect across treatments. These data are novel in demonstrating the trajectory of AN symptom remission throughout PFT, and also provide novel insights into the trajectory of affective functioning throughout PFT and FBT.

The notion that weight gain and dietary restraint improve at a comparable rate throughout FBT and PFT was not anticipated, given the superior EOT remission rates in PFT (Le Grange et al., 2016). This may reflect the broader indices of eating disorder psychopathology captured in EOT data in the FBT vs. PFT RCT, perhaps suggesting that the trajectories of other facets of eating disorder psychopathology improve faster in PFT. Nevertheless, the equally rapid improvement in weight status and dietary restraint across FBT and PFT is noteworthy, and lends support to the efficacy of PFT in the treatment of adolescent $\mathrm{AN}$. In essence, FBT is a largely behavioral treatment that rests on the interventive efforts of parents to promote weight normalization without an explicit focus on strategies relating to cognitive symptom remission. The combination of weight normalization and the parent-driven interruption of AN behavioral symptoms is in turn thought to drive cognitive symptom remission (Hildebrandt et al., 2012). The present data suggest that the absence of adolescents from treatment sessions does not impinge upon these processes throughout PFT.

With respect to affective functioning, increments in positive affect and reductions in negative affect were comparable across FBT and PFT. While inconsistent with broader treatments for childhood mood disorders which posit that both adolescents and parents attend treatment to promote optimal outcomes (Cobham, Dadds, Spence \& McDermott, 
2010; Wood et al., 2006), these findings are consistent with data illustrating the normalization of mood-related symptoms in those with AN upon weight restoration (Meehan et al., 2006). Further advancing this notion, our study indicates linear improvements in positive affect and linear reductions in negative affect alongside increments in weight, which is an important finding in dispelling misnomers around the assumed aversive affective consequences of patient weight gain. Further still, these data suggest that behavioral treatments for adolescents with AN contribute to adaptive trends in negative and positive affect, despite not targeting these factors directly, or necessarily involving the adolescent in treatment. Cumulatively, these data underscore the salience of targeting the behavioral symptoms of AN in treatment.

Strengths of the study include the large sample size, the rigorous randomized clinical trial design, and the manualized treatment for both study arms. However, several limitations are noteworthy. Stratification of symptom trajectories by AN subtype would be instructive. Further, use of the Dietary Restraint scale of the EDE-Q as a proxy for cognitive ED psychopathology during fortnightly measurements, while effective in minimizing patient burden, precluded analyses of other dimensions of cognitive ED psychopathology throughout treatment. Given the superior EOT remission rates of PFT versus FBT, it is possible that other dimensions of cognitive AN psychopathology, which were not recorded at such regular intervals, followed differential trajectories throughout treatment, although this possibility remains an important question for future research. Also, given the state-related transience of both positive and negative affective states, more frequent data collection points may allow for better detection of transitory shifts in affect throughout treatment. Lastly, on average, these adolescents were not profoundly low in bodyweight, although this is typical of an outpatient adolescent population. These limitations notwithstanding, the present study suggests that (i) the absence of adolescents 
Symptom Trajectories in Two Treatments for Anorexia 10

from treatment sessions does not undermine treatment mechanisms around weight gain and AN symptom remission, and (ii) that positive increments in affect may be achieved throughout both FBT and PFT, despite the absence of a specific focus on affective functioning.
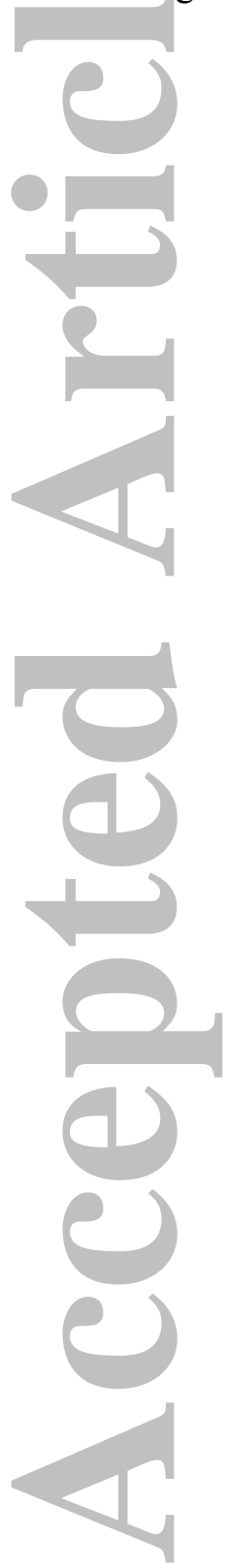


\section{References}

Cobham, V. E., Dadds, M. R., Spence, S. H., \& McDermott, B. (2010). Parental anxiety in the treatment of childhood anxiety: A different story three years later. Journal of Clinical Child \& Adolescent Psychology, 39, 410-420.

Cooper, Z., \& Fairburn, C. G. (1987). The Eating Disorders Examination: A semistructured interview for the assessment of the specific psychopathology of eating disorders. International Journal of Eating Disorders, 6, 1-8.

Doyle, P. M., Le Grange, D., Loeb, K. L., Doyle, A. C., \& Crosby, R. D. (2010). Early response to family-based treatment for adolescent anorexia nervosa. International Journal of Eating Disorders, 43, 659-662.

Eisler, I., Dare, C., Hodes, M., Russell, G. F. M., Dodge, E., \& Le Grange, D. (2000). Family therapy for adolescent anorexia nervosa: The results of a controlled comparison of two family interventions. Journal of Child Psychology and Psychiatry, 41, 727-736.

Fairburn, C. G., \& Beglin, S. J. (1994). Assessment of eating disorders: Interview of selfreport questionnaire? International Journal of Eating Disorders, 16, 363-370.

Federici, A., \& Kaplan, A. S. (2008). The patient's account of relapse and recovery in anorexia nervosa: A qualitative study. European Eating Disorders Review, 16, 1-10. Hildebrandt, T., Bacow, T., Markella, M., \& Loeb, K. L. (2012). Anxiety in anorexia nervosa and its management using family-based treatment. European Eating Disorders Review, 20, e1-e16.

Hughes, E. K., Le Grange, D., Court, A., Yeo, M. S. M., Campbell, S., Allan, E., Crosby, R. D., Loeb, K. L., \& Sawyer, K. L. (2014). Parent-focused treatment for adolescent anorexia nervosa: A study protocol of a randomized controlled trial. BMC Psychiatry, 14:105. 
Symptom Trajectories in Two Treatments for Anorexia 12

Hughes, E. K., Sawyer, S. M., Loeb, K. L., \& Le Grange, D. (2015). Parent Focused

Treatment. In Loeb, K. L., Lock, J., \& Le Grange (Eds.). Family Therapy for Adolescent

Eating and Weight Disorders: New Applications, p.59-72. Routledge; New York.

Lavender, J. M., De Young, K. P., Wonderlich, S. A., Crosby, R. D., Engel, S. G., Mitchell,

J. E., Crow, S. J., Peterson, C. B., \& Le Grange, D. (2013). Daily patterns of anxiety in

anorexia nervosa: Associations with eating disorder behaviors in the natural environment.

Journal of Abnormal Psychology, 122, 672-683.

Le Grange, D., Eisler, I., Dare, C., \& Russell, G. F. M. (1992). Evaluation of family

treatments in adolescent anorexia nervosa: A pilot trial. International Journal of Eating

Disorders, 12, 347-357.

Le Grange, D., Hughes, E. K., Court, A., Yeo, M., Crosby, R. D., \& Sawyer, S. M. (2016).

Randomized clinical trial of parent-focused therapy and family-based treatment for

adolescent anorexia nervosa. Journal of the American Academy of Child \& Adolescent

Psychiatry, 55, 683-692.

Le Grange, D., Lock, J., Accurso, E. C., Agras, W. S., Darcy, A., Forsberg, S., \& Bryson,

W. S. (2014). Relapse from remission at two-to four-year follow-up in two treatments for adolescent anorexia nervosa. Journal of the American Academy of Child \& Adolescent

Psychiatry, 53, 1162-1167.

Lock, J., \& Le Grange, D. Treatment Manual for Anorexia Nervosa: A Family-Based

Approach, $2^{\text {nd }}$ Edition. (2013). Guilford Press: New York, London.

Lock, J., Le Grange, D., Agras, W. S., Moye, A., Bryson, S. W., \& Booil, J. (2010).

Randomized clinical trial comparing family-based treatment with adolescent focused

individual therapy for adolescents with anorexia nervosa. Archives of General Psychiatry

$67,1025-1032$.

International Journal of Eating Disorders

This article is protected by copyright. All rights reserved. 
Meehan M. A., Loeb, K. L., Roberto, C. A., \& Attia, E. (2006). Mood change during weight restoration in patients with anorexia nervosa. International Journal of Eating Disorders, 39, $587-589$.

Mond, J. M., Hay, P. J., Owen, C., \& Beumont, P. J. V. (2004). Validity of the Eating Disorder Examination Questionnaire (EDE-Q) in screening for eating disorders in community samples. Behavior Research and Therapy, 42, 551-567.

Watson, D., Clark, L. A., \& Tellegen, A. (1988). Development and validation of brief measures of Positive and Negative Affect: The PANAS Scales. Journal of Personality \& Social Psychology, 54, 1063-1070.

Wood, J. J., Piacentini, J. C., Southam-Gerow, M., Chu, B. C., \& Sigman, M. (2006).

Family cognitive behavioral therapy for child anxiety disorders. Journal of the American Academy of Child \& Adolescent Psychiatry, 45, 314-321.

International Journal of Eating Disorders This article is protected by copyright. All rights reserved. 
Symptom Trajectories in Two Treatments for Anorexia 14

Table 1. Results of analyses predicting symptom trajectory over course of treatment.

\begin{tabular}{|c|c|c|c|c|}
\hline Model & Time & & Level-1 & Level-2 \\
\hline \multirow[t]{4}{*}{ Weight } & Intercept (treatment onset) & $\beta(S E)$ & $45.83(0.67)$ & $1.19(0.66)$ \\
\hline & & T-ratio & $68.34^{* *}$ & 1.80 \\
\hline & Slope (rate of change) & $\beta(S E)$ & $0.33(0.02)$ & $0.01(0.02)$ \\
\hline & & T-ratio & $15.38^{* *}$ & 0.46 \\
\hline \multirow[t]{4}{*}{ Dietary Restraint } & Intercept (treatment onset) & $\beta(S E)$ & $1.78(0.20)$ & $0.26(0.20)$ \\
\hline & & T-ratio & $9.01 * *$ & 1.33 \\
\hline & Slope (rate of change) & $\beta(S E)$ & $-0.03(0.01)$ & $-0.01(0.01)$ \\
\hline & & T-ratio & $-3.62 * *$ & -1.30 \\
\hline \multirow[t]{4}{*}{ Negative Affect } & Intercept (treatment onset) & $\beta(S E)$ & $2.56(0.11)$ & $-0.02(0.11)$ \\
\hline & & T-ratio & $23.04 * *$ & -0.14 \\
\hline & Slope (rate of change) & $\beta(S E)$ & $-0.04(0.01)$ & $-0.01(0.01)$ \\
\hline & & T-ratio & $-6.48 * *$ & -0.79 \\
\hline \multirow[t]{4}{*}{ Positive Affect } & Intercept (treatment onset) & $\beta(S E)$ & $2.36(0.08)$ & $-0.05(0.08)$ \\
\hline & & T-ratio & $28.89 * *$ & -0.54 \\
\hline & Slope (rate of change) & $\beta(S E)$ & $0.03(0.01)$ & $0.01(0.01)$ \\
\hline & & T-ratio & $4.83 * *$ & 1.019 \\
\hline
\end{tabular}

Note: Level-1 model dfs ranged from 85 to 102 . Level-2 dfs ranged from 84 to $101 .{ }^{*} p<$

$.05, * * p<.001$

International Journal of Eating Disorders

This article is protected by copyright. All rights reserved. 
Figure 1. Symptom trajectories over the course of treatment representing average scores of each measure for the entire sample across the course of treatment. Average scores modelled below include both patients in the PFT and FBT groups. . Error bars indicate 95\% confidence intervals.
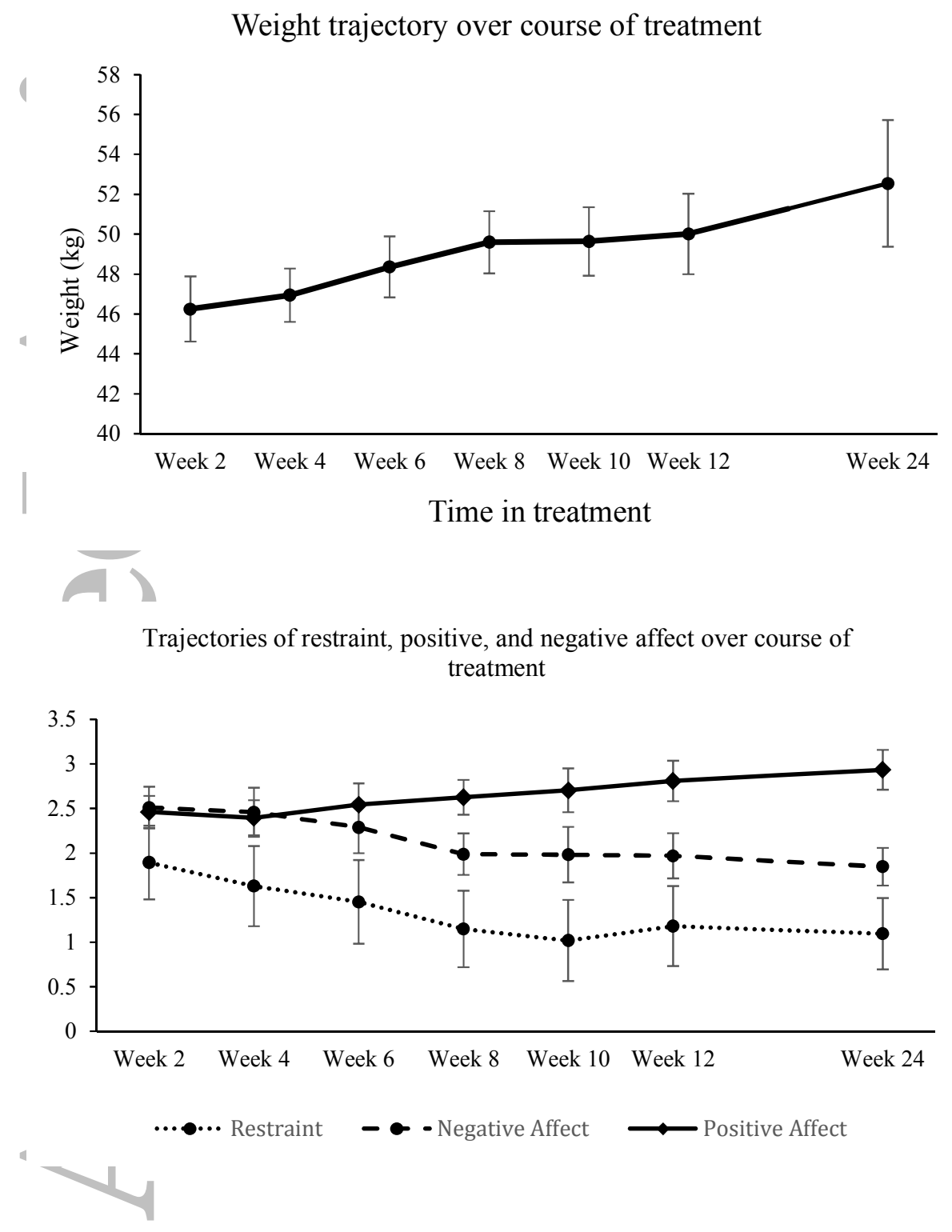

International Journal of Eating Disorders 


\section{University Library}

\section{- M M N E R VA A gateway to Melbourne's research publications}

Minerva Access is the Institutional Repository of The University of Melbourne

Author/s:

Murray, SB;Pila, E;Le Grange, D;Sawyer, SM;Hughes, EK

Title:

Symptom trajectories throughout two family therapy treatments for adolescent anorexia nervosa

Date:

2017-11-01

Citation:

Murray, S. B., Pila, E., Le Grange, D., Sawyer, S. M. \& Hughes, E. K. (2017). Symptom trajectories throughout two family therapy treatments for adolescent anorexia nervosa. INTERNATIONAL JOURNAL OF EATING DISORDERS, 50 (11), pp.1323-1327. https:// doi.org/10.1002/eat.22776.

Persistent Link:

http://hdl.handle.net/11343/293459 